\section{Palm to finger ulnar sensory nerve conduction}

\author{
Eduardo Davidowich, 1 \\ Osvaldo J.M. Nascimento, 1 Marco Orsini, 1 \\ Camila Pupe,1 Bruno Pessoa,1 \\ Caroline Bittar,1 Karina Lebeis Pires,1 \\ Carlos Bruno, 1 Bruno Mattos Coutinho, 1 \\ Olivia Gameiro de Souza, 1 \\ Pedro Ribeiro,2 Bruna Velasques,2 \\ Juliana Bittencourt,2 Silmar Teixeira,3 \\ Victor Hugo Bastos 3
}

1Antônio Pedro University Hospital, Fluminense Federal University, Niterói; 2Laboratório de Mapeamento Cerebral, Rio de Janeiro Federal University; 3Universidade Federal do Piaiu, Parnaiba, Brazil

\section{Abstract}

Ulnar neuropathy at the wrist (UNW) is rare, and always challenging to localize. To increase the sensitivity and specificity of the diagnosis of UNW many authors advocate the stimulation of the ulnar nerve (UN) in the segment of the wrist and palm. The focus of this paper is to present a modified and simplified technique of sensory nerve conduction (SNC) of the UN in the wrist and palm segments and demonstrate the validity of this technique in the study of five cases of type III UNW. The SNC of UN was performed antidromically with fifth finger ring recording electrodes. The UN was stimulated $14 \mathrm{~cm}$ proximal to the active electrode (the standard way) and $7 \mathrm{~cm}$ proximal to the active electrode. The normal data from amplitude and conduction velocity (CV) ratios between the palm to finger and wrist to finger segments were obtained. Normal amplitude ratio was 1.4 to 0.76 . Normal $\mathrm{CV}$ ratio was 0.8 to 1.23 .We found evidences of abnormal SNAP amplitude ratio or substantial slowing of UN sensory fibers across the wrist in 5 of the 5 patients with electrophysiological-definite type III UNW.

\section{Introduction}

Ulnar neuropathy at the wrist (UNW) is rare, and always challenging to localize electro-physiologically. The standard approach has been the demonstration of prolonged distal motor latency to first dorsal interosseous (FDI) and abductor digiti minimi (ADM) in conjunction with a normal dorsal branch of the ulnar nerve (DBUN) sensory nerve action potential (SNAP), abnormal ulnar SNAP in fifth finger and denervation on needle EMG of ulnar inner- vated hand muscles with sparing of ulnar innervated muscles proximal to the wrist.1To increase the sensitivity and specificity of the diagnosis of UNW many authors advocate the stimulation of the ulnar nerve (UN) in the segment of the wrist and palm, some techniques using short-segment interval (centimeter by centimeter), other using larger segments. Both sensory and motor responses were studied.1-6 After crossing the elbow, the ulnar nerve gives motor innervation to the flexor carpi ulnaris and flexor digitorium profundus. As it descends in the forearm, the dorsal cutaneous branch originates about $8 \mathrm{~cm}$ proximal to the ulnar styloid. The next branch, the palmar cutaneous branch, originates at the level of the ulnar styloid. The ulnar nerve then enters the canal of Guyon. Within the canal of Guyon the ulnar trunk divides into the superficial sensory and deep motor branches. Lesions of the distal ulnar nerve can occur at any site along this course, involving proximal branches just proximal to Guyon's canal to the most distal lesions of the deep motor branch innervating the FDI muscle. ${ }^{7}$

The focal involvement of the ulnar nerve at the wrist can manifest itself in many ways. Shea and McClain and, 8 later, Gross and Gelberman, ${ }^{9}$ studied the relationship between the symptoms of ulnar neuropathy and the anatomic location of nerve compression about the wrist. They classified compressive UNW into 3 types. Type I syndrome, a result of nerve compression proximal to or within Guyon's canal, before any nerve bifurcation, and manifests as motor weakness of all the ulnar innervated intrinsic muscles and sensory deficits over the hypothenar eminence and the small and ring digits. Type II syndrome, manifests exclusively as motor weakness of the hand without any sensory impairment. Type III syndrome occurs secondary to compression of the superficial sensory branch of the ulnar nerve and manifests as isolated sensory loss.10,11 Study of large series of patients with UNW demonstrated that the type II syndrome is the most frequent, followed by the type I. The type III syndrome is the less frequent. ${ }^{5}$ Our objective is to report a modified and simplified technique of sensory nerve conduction (SNC) of the UN in the wrist and palm segments demonstrating the validity of this technique in five cases of type III UNW.

\section{Materials and Methods}

\section{Electrodiagnostic technique}

The SNC of UN was performed antidromically to obtain SNAP with fifth finger ring recording electrodes. The active electrode was placed
Correspondence: Osvaldo J.M. Nascimento, Federal Fluminense University, Rua Siqueira Campos, 53/1204, Copacabana, CEP 22031071, Rio de Janeiro, RJ, Brazil.

E-mail: osvaldo_nascimento@hotmail.com

Key words: Ulnar nerve; wrist; neuropathy; nerve conduction.

Contributions: the authors contributed equally.

Conflict of interest: the authors declare no potential conflict of interest.

Received for publication: 17 September 2015. Revision received: 2 November 2015.

Accepted for publication: 12 December 2015.

This work is licensed under a Creative Commons Attribution NonCommercial 3.0 License (CC BYNC 3.0).

(C) Copyright E. Davidowich et al., 2015

Licensee PAGEPress, Italy

Neurology International 2015; 7:6207

doi:10.4081/ni.2015.6207

over the proximal interphalangeal joint of the fifth finger. The reference electrode was placed two centimeters distal to the active electrode. The ground electrode was placed on the dorsum of the hand. The UN was stimulated $14 \mathrm{~cm}$ proximal to the active electrode (the standard way) and $7 \mathrm{~cm}$ proximal to the active electrode. The use of standard distances $(7$ and $14 \mathrm{~cm}$ ) facilitates the interpretation of the normality parameters based on latency and amplitude (Figure 1). The filter was set at a low-frequency of $20 \mathrm{~Hz}$ and high-frequency of $2 \mathrm{kHz}$, sensitivity at $20 \mathrm{mV} /$ division and sweep speed at 1 $\mathrm{ms} /$ division. Negative peak latency, baselineto-negative peak amplitude, and conduction velocity (CV) using the take off latency were measured. The amplitude and $\mathrm{CV}$ ratios between the palm to finger segment $(7 \mathrm{~cm})$, divided by the wrist to finger segment $(14 \mathrm{~cm})$ were calculated. The skin temperature was maintained above $32^{\circ} \mathrm{C}$.

\section{Normative data}

Normative data for the SNC of the ulnar nerve at the wrist and palm used in our laboratory were obtained from a population of 48 individuals, aged 26-76 years (mean 42.6), without clinical or electrophysiology evidence of ulnar nerve lesion and no history of systemic disease. Out of this 48 individuals, 24 were male and 24 female. Each one contributed with only one hand, right or left, for our data. We use 12 male right hands, 12 male left hands, 12 female right hands and 12 female left hands.

The mean value and standard deviation (SD) were calculated for each of the variables 
described in the section examination technique. Normative values were reported as the mean \pm 2 SD. This study was approved by the ethical committee in our institution and informedconsent was obtained from each subject.

\section{Patients}

Between February 2012 and October 2013 five patients had the diagnosis of type III UNW in the EDX lab of the Neurology/Neuroscience Clinical Research Sub-Unit and Lab of Antonio Pedro University Hospital - NeuroUPC. All of them complained of numbness in the fourth and fifth finger and had no complaints in the region supplied by DBUN. In all the UN motor conduction (MNC) was normal in the ADM and FDI with stimulation at the wrist, below the elbow and above the elbow. None of the patients showed alterations in the needle EMG of ulnar innervated muscles.

\section{Results}

\section{Normative data}

The default values for our laboratory are described in Table 1.

The amplitude, latency and CV for UN NCS at $14 \mathrm{~cm}$ obtained in our series are compatible with those described in the literature. ${ }^{12}$ The amplitude, latency and CV at $7 \mathrm{~cm}$ cannot be directly compared with other databases. In finger-wrist segment and in finger-palm segment the sample variance was much greater in amplitude than in latency or CV. The lowest variances were found in $\mathrm{CV}$ ratio and in ampli- tude ratio.

Since the goal of this technique is to evaluate the occurrence of focal involvement of the UN in the wrist to palm segment, special attention was given to the analysis of CV and amplitude ratios between the palm to finger and wrist to finger segments. In our data values greater than 1.4 for amplitude ratio are abnormal and identified as abnormal SNAP amplitude ratio (ASAR) in the wrist to palm seg-

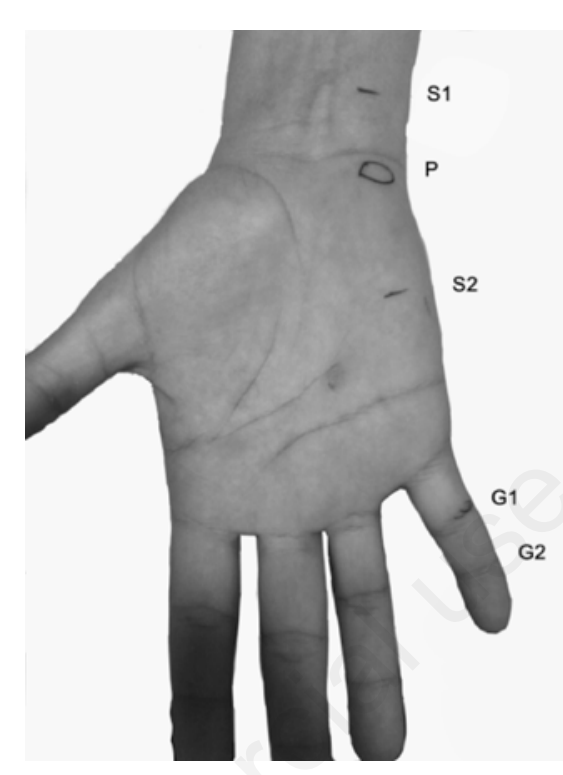

Figure 1. Electrode montage for wrist to finger and palm to finger ulnar sensory nerve conduction. S1: Wrist stimulus point; P: Pisiform bone; S2: Palm stimulus point; G1: Active recorder electrode; G2: Reference recorder electrode. ment. Amplitude ratio smaller than 0.76 is suggestive of technical mistake due to an incomplete stimulation in the wrist segment.

The normal CV ratio ranged from 0.8 to 1.23 . Values greater than 1.23 are suggestive of focal slowing in the wrist to palm segment. Values below 0.8 are suggestive of slowing in the palm to finger segment.

\section{Patients}

In all five patients the UN motor conduction (MNC) was normal in the ADM and FDI with stimulation at the wrist, below the elbow and above the elbow. Side to side comparison of distal motor latency to the FDI and ADM did not show significant differences.

None of the patients showed alterations in the needle EMG of ulnar innervated muscles. The values for UN SNC at symptomatic side for all 5 patients are described in Table 2.

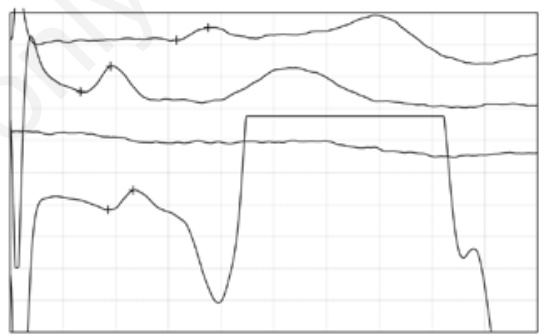

Figure 2. Traces from patient 1 right ulnar sensory nerve conduction. Upper trace: 14 $\mathrm{cm}$ wrist to fifth finger, present with prolonged latency and reduced amplitude $(3.76 \mathrm{~ms} / 7.7 \mu \mathrm{V})$. Second trace: $7 \mathrm{~cm}$ palm to finger normal SNAP $(1.91 \mathrm{~ms} / 15.7 \mu \mathrm{V})$. Third trace: intentionally without waves. Fourth trace: normal DBUN $(2.23 \mathrm{~ms} / 12.1$ $\mu \mathrm{V})$.

Table 1. Normal values of ulnar nerve sensory nerve conduction study at the wrist and palm in 48 hands.

\begin{tabular}{lcccccc} 
& Unit & Mean & SD & 土2 SD & HNV & LNV \\
Wrist-finger $14 \mathrm{~cm}$ latency & $\mathrm{ms}$ & 3.02 & 0.18 & $2.8-3.4$ & 3.4 & $\mathrm{NA}$ \\
Wrist-finger $14 \mathrm{~cm}$ amplitude & $\mu \mathrm{V}$ & 38 & 13.75 & $10-51$ & $\mathrm{NA}$ & 10 \\
\hline Wrist-finger $14 \mathrm{~cm} \mathrm{CV}$ & $\mathrm{m} / \mathrm{s}$ & 59 & 4.64 & $50-68$ & $\mathrm{NA}$ & 50 \\
Palm-finger $7 \mathrm{~cm}$ latency & $\mathrm{ms}$ & 1.78 & 0.15 & $1.5-2.0$ & 2.0 & $\mathrm{NA}$ \\
\hline Palm-finger $7 \mathrm{~cm}$ amplitude & $\mu \mathrm{V}$ & 41 & 16.62 & $8-75$ & $\mathrm{NA}$ & 8 \\
Palm-finger $7 \mathrm{~cm}$ CV & $\mathrm{m} / \mathrm{s}$ & 57.8 & 6.68 & $45-71$ & $\mathrm{NA}$ & 45 \\
\hline $7 \mathrm{~cm} / 14 \mathrm{~cm}$ amplitude ratio & $\mathrm{NA}$ & 1.08 & 0.16 & $0.76-1.4$ & 1.4 & 0.76 \\
$7 \mathrm{~cm} / 14 \mathrm{~cm}$ velocity ratio & $\mathrm{NA}$ & 0.97 & 0.081 & $0.8-1.23$ & 1.23 & 0.8 \\
\hline
\end{tabular}

SD, standard deviation; HNV, highest normal value; LNV, lower normal value; NA, not applicable.

Table 2. Values of ulnar sensory nerve conduction study at the wrist and palm in patients with type III ulnar neuropathy of the wrist.

\begin{tabular}{|c|c|c|c|c|c|c|c|c|c|c|c|}
\hline & Sex & Side & Age & $14 \mathrm{~cm} \mathrm{~L}$ & $14 \mathrm{~cm} \mathrm{~A}$ & $14 \mathrm{~cm} \mathrm{~V}$ & $7 \mathrm{~cm} \mathrm{~L}$ & $7 \mathrm{~cm} \mathrm{~A}$ & $7 \mathrm{~cm} \mathrm{~V}$ & 7/14 AR & $7 / 14 \mathrm{VR}$ \\
\hline 1 & M & Right & 50 & 3.76 & 7.7 & 44.3 & 1.91 & 15.7 & 52.2 & 2.03 & 1.18 \\
\hline 2 & $\mathrm{~F}$ & Left & 78 & 3.6 & 14.8 & 47.6 & 1.6 & 11.6 & 60.3 & 0.79 & 1.27 \\
\hline 3 & $\mathrm{~F}$ & Right & 75 & NO & NO & NO & 1.96 & 20 & 56 & NA & $\mathrm{NA}$ \\
\hline 4 & $\mathrm{~F}$ & Right & 45 & 3.8 & 6.5 & 48.3 & 2 & 16 & 64.8 & 2.46 & 1.34 \\
\hline 4 & $\mathrm{~F}$ & Left & 45 & 3.9 & 2.2 & 42.4 & 1.81 & 12 & 67.3 & 5.45 & 1.59 \\
\hline 5 & M & Left & 71 & 3.8 & 14 & 47.5 & 2,0 & 23 & 48.3 & 1.64 & 1.01 \\
\hline
\end{tabular}

M, male; F, female; L, latency; A, amplitude; V, Velocity; AR, amplitude ratio; VR, velocity ratio; NO, not obtained; NA, not applicable. 


\section{Patient 1}

Patient 1 was a 50 year old man. The standard right UN SNC present with prolonged latency and reduced amplitude $(3.76 \mathrm{~ms} / 7.7$ $\mu \mathrm{V})$. The right DBUN was normal $(2.3 \mathrm{~ms} / 12.2$ $\mu \mathrm{V}$ ) and no other abnormality was found on electrodiagnostic evaluation (EDX).

The palm to finger right UN SNC revealed a normal SNAP $(1.91 \mathrm{~ms} / 15.7 \mu \mathrm{V})$. The amplitude ratio was 2.03 clearly suggestive of ASAR in the segment wrist to palm. The $\mathrm{CV}$ ratio was 1.18 , within normal limits. The traces from patient 1 are represented in Figure 2

\section{Patient 2}

Patient 2 was a 78 year old female. The standard left UN SNC present withslightly prolonged latency and normal amplitude (3.6 $\mathrm{ms} / 14.8 \mu \mathrm{V})$. The DBUN SNAP was not obtained bilaterally. The EDX also showed prolongation of distal motor and sensory latencies of the right median nerve and prolonged sensory latency of the left median nerve. The right UN SNC was normal $(3.0 \mathrm{~ms} / 19.7 \mu \mathrm{V})$.

The palm to finger left UN SNC revealed a normal SNAP $(1.6 \mathrm{~ms} / 11.6 \mu \mathrm{V})$. The amplitude ratio was 0,79 , within normal limits. The $\mathrm{CV}$ ratio was 1.27 indicating slowing in wrist to palm segment.

\section{Patient 3}

Patient 3 was a 75 year old female with a history of type II diabetes and complained of paresthesia in the lower limbs and numbness in the fourth and fifth fingers of the right hand. The standard right UN SNC presented with no response. The DBUN SNAP was normal. The EDX also showed slightly reduced amplitude of sural SNAP compatible with mild sensory neuropathy, no other abnormality was found. The left UN SNC was normal (3.2 ms/32 $\mu \mathrm{V})$.

The palm to finger right UN SNC revealed a normal SNAP $(1.96 \mathrm{~ms} / 20 \mu \mathrm{V})$. These data are suggestive of complete ASAR in the wrist to palm segment.

\section{Patient 4}

Patient 4 was a 45 year old female. The EDX was normal except for UN SNC in the fifth finger which was abnormal. The standard UN SNC presented with prolonged latency and reduced amplitude bilaterally (right: $3.8 \mathrm{~ms} / 6.5$ $\mu \mathrm{V}$; left: $3.9 \mathrm{~ms} / 2.2 \mu \mathrm{V})$.

The palm to finger UN SNC revealed normal SNAP bilaterally (right: $2.0 \mathrm{~ms} / 16 \mu \mathrm{V}$; left: 1.8 $\mathrm{ms} / 12 \mu \mathrm{V}$ ). The amplitude ratio was 2.46 for the right side and 5.45 for the left side, clearly suggestive of ASAR in the segment wrist to palm. The $\mathrm{CV}$ ratio was 1.34 for the right side and 1.59 for the left side, indicating bilateral slowing in wrist to palm segment.

\section{Patient 5}

Patient 5 was a 71 year old male. The standard left UN SNC presented with prolonged latency and normal amplitude $(3.8 \mathrm{~ms} / 14.0$ $\mu \mathrm{V})$. The DBUN SNAP was normal bilaterally. The EDX also revealed bilateral abolition of the median nerves SNAP, prolongation of distal motor latencies of the left median nerve and abolition of the right median nerve motor response. The right UN SNC was normal (3.3 $\mathrm{ms} / 26 \mu \mathrm{V})$.

The palm to finger left UN SNC revealed a normal SNAP $(2.0 \mathrm{~ms} / 23 \mu \mathrm{V})$. The amplitude ratio was 1.64, suggestive of ASAR in the wrist to palm segment. The $\mathrm{CV}$ ratio was 1.01 , within normal limits.

\section{Discussion}

ASAR in the wrist to palm segment refers to an apparent conduction block of sensory fibers of the UN between the palm and wrist. Sensory conduction block probably occur, however it is not well defined in practical terms as in the motor conduction block, and temporal dispersal may be important in the drop of the SNAP amplitude.

The major finding in this study was that ASAR or substantial slowing of UN sensory fibers across the wrist was observed in 5 of the 5 patients (100\%) with electrophysiologicaldefinite type III UNW. The values found in our patients were clearly beyond our normal limits.

Traditional measures such as abnormal ulnar wrist to fifth finger SNAP, normal DBUN SNAP and normal UN MNC were sufficient to determine type III UNW in the majority of patients. However, the standard techniques are not able to determine the occurrence of ASAR or to determine the precise location of the lesion in the wrist to palm segment.

The preservation of a normal response of the DBUN SNAP is an important milestone in determining the UNW. However the occurrence of anatomical variations can lead to the abolition of the DBUN SNAP in normal subjects, leading to diagnostic challenges.

Laws and Wells, in 2008, studied the occurrence of anatomical variation between the DBUN and radial superficial nerve (RSN) in 100 patients with no evidence of injury to the radial or ulnar nerves. Of these 100 patients, 16 had low amplitude or no response of DBUN SNAP. In 13 of these patients the occurrence of anatomical variation with the NRS can be confirmed as the cause for this abnormality. In cases of UNW, the occurrence of this variation is particularly dangerous because the examiner may suggest that the lesion is more proximal.13

Laws, Stetkarova and Wells, in 2010, reported two cases which had coexistence of Martin-
Gruber Anastomosis, simulating a conduction block of the ulnar nerve in the forearm, and DBUN-RSN anatomic variation generating abolition of the DBUN SNAP. These findings, taken together, can lead to misinterpretation, simulating an ulnar neuropathy at the elbow or forearm. ${ }^{14}$

The addition of a SNC technique that can determine UNW independently of the DBUN SNAP increases the sensitivity and specificity of the electrodiagnostic evaluation, especially in type III UNW, where the MNC is normal.

In our laboratory the performance of an additional stimulus for the palm during the UN SNC do not added time or discomfort to EDX and generated important data to confirm UNW when it is present. For optimal functioning of our technique the wrist point of stimulation should be placed at least $2 \mathrm{~cm}$ proximal to the pisiform bone and the palm point of stimulation should be placed at least $3 \mathrm{~cm}$ distal to the pisiform bone. In most persons, the distances of 7 and $14 \mathrm{~cm}$ of the proximal interphalangeal joint put the stimulus points within the ideal range. For very large or very small hands we recommend the use of larger or smaller distances ( 8 and $16 \mathrm{~cm}$ or 6 and $12 \mathrm{~cm}$ ). In this situation the normative values of latency cannot be used. The amplitude and conduction velocity ratios between the finger-palm and finger- wrist segments normal data can be useful.

\section{Conclusions}

The evaluation of SNC of the ulnar nerve in the wrist-finger and palm-finger segments is a simple and fast technique, which in addition to the standard techniques is useful in the evaluation of ulnar neuropathy at the wrist.

\section{References}

1. Cowdery SR, Preston DC, Herrmann DN, Logigian EL. Electrodiagnosis of ulnar neuropathy at the wrist conduction block versus traditional tests. Neurology 2002;13:420-7.

2. McIntosh KA, Preston DC, Logigian EL. Short-segment incremental studies to localize ulnar nerve entrapment at the wrist. Neurology 1998;50:303-6.

3. Kmura J. Electrodiagnosis. In: Diseases of nerve and muscle. 3rd ed. New York: Oxford University Press, Inc; 2001. pp 141148.

4. Kim D, Kang Y, Hwang M, et al. Reference values of fractionated neurography of the ulnar nerve at the wrist in healthy subjects. Clin Neurophysiol 2005;116:2853-7. 
5. Seror P. Electrophysiological pattern of 53 cases of ulnar nerve lesion at the wrist. Clin Neurophysiol 2013;43:95-103.

6. Seror P, Vuillemin V. Ulnar nerve lesion at the wrist related to pisotriquetral joint arthropathy. Muscle Nerve 2013;47:600-4.

7. Lo YL, Ratnagopal P, Leoh TH, et al. Clinical and electrophysiological aspects of distal ulnar neuropathy. Acta Neurol Scand 2002;105:309-94.

8. Shea JD, McClain EJ. Ulnar-nerve compression syndromes at and below the wrist. J Bone Joint Surg Am 1969;51:1095103.

9. Gross MS, Gelberman RH. The anatomy of the distal ulnar tunnel. Clin Orthop Relat Res 1985;196: 238-47.

10. Bachoura A, Jacoby SM. Ulnar tunnel syndrome. Orthop Clin North Am 2012;43:46774.

11. Dumitru D, Amato A, Zwarts M. Electrodiagnostic medicine. 2nd ed. Philadelphia: Hanley \& Belfus Inc; 2002. pp 1083-5.
12. DeLisa JA, Lee HJ, Baran EM, et al. Manual of nerve conduction velocity and clinical neurophysiology. 3rd ed. Lippincott Williams \& Wilkins; 1994. pp 100-1.

13. Leis AA, Wells KJ. Radial nerve cutaneous innervation to the ulnar dorsum of the hand. Clin Neurophysiol 2008;119:662-6.

14. Leis AA, Stetkarova I, Wells KJ. MartinGruber anastomosis with anomalous superficial radial innervation to ulnar dorsum of hand: a pitfall when common variants coexist. Muscle Nerve 2010;41:313-7. 